\title{
ASSESSMENT OF LAND USE AND LAND COVER CHANGE DETECTION BY USING REMOTE SENSING AND GIS TECHNIQUES IN THE COASTAL DESERTS, SOUTH OF IRAN
}

\author{
S. A. R. Hosseini ${ }^{*}$, H. Gholami², Y. Esmaeilpoor ${ }^{2}$ \\ ${ }^{1}$ Dept. of Natural Resources Engineering, University of Hormozgan,banda abbas, Iran - \\ ar.hosseini.phd@hormozgan.ac.ir \\ 2 Dept. of Natural Resources Engineering, University of Hormozgan,banda abbas, Iran - \\ hamidgholami@ut.ac.ir, y.esmaeilpour@hormozgan.ac.ir
}

KEY WORDS: Land use / cover, Coastal Desert, Landsat, Chabahar, Konarak, Iran

\begin{abstract}
Land use/land cover (LULC) changes have become a central issue in current global change and sustainability research. Due to the large expanse of land change detection by the traditional methods is not sufficient and efficient; therefore, using of new methods such as remote sensing technology is necessary and vital This study evaluates LULC change in chabahar and konarak Coastal deserts, located in south of sistan and baluchestan province from 1988 to 2018 using Landsat images. Maximum likelihood classification were used to develop LULC maps. The change detection was executed using post-classification comparison and GIS. Then, taking ground truth data, the classified maps accuracy were assessed by calculating the Kappa coefficient and overall accuracy. The results for the time period of 1988 - 2018 are presented. Based on the results of the 30-year time period, vegetation has been decreased in area while urban areas have been developed. The area of saline and sandy lands has also increased.
\end{abstract}

\section{Introduction}

Land use/land cover (LULC) changes have become a central issue in current global change and sustainability research (Abdullah et al., 2014). Land cover is defined as a physical and biological cover of the earth's surface that contains water, vegetation and bare soil. Land use and cover changes are among the most important changes on the land surface which have considerable influence on the environment and environmental processes. Thus, LUCC are recognized as the main driving force of the global ecosystem change (Behera et al., 2012). Land use change is rooted in the spatiotemporal interaction between biophysical and human aspects (Dubovyk et al., 2011). Forest destruction, desertification, destruction of fertile agricultural lands and uncontrolled urban development are some of the phenomena that threaten the environmental balance directly and indirectly (azizi etal ., 2016). Limiting factors in arid areas such as water shortage and soil salinity are important factors to study the occurred changes in land cover Due to the large expanse of land, change detection by the traditional methods is not sufficient and efficient; therefore, using of new methods such as remote sensing technology is necessary and vital (Giveii Ashraf, 2013). Remote Sensing means the ability to detect change on the earth's surface through space-borne sensors (Ramachandra \& U. Kumar, 2004) Geographic Information System is a useful tool for measuring the change between two or more time periods. It has the ability to incorporate multi-sources of data into a change detection plat form (Ramachandra \& Kumar, 2004) Remotely sensed data and GIS are widely used for de - tecting land use and land cover changes. Many studies have attempted to use remotely sensed data and GIS to address land use change detection (Weng, 2002). Robles and Luna, (2011) investigated land use change dynamics in the Zhujiang Delta south China and the Northern Coastal Region of Nayarit, Mexico respectively using satellite imagery, GIS and stochastic modelling technologies and they concluded that the integration of satellite data and GIS is an effective approach for analysing the direction, rate and spatial pattern of land use change. This paper aims to explore and analyze the characteristics of LULC changes in the coastal desert cities of chabahar, konarak and sistan and baluchestan Province, using Landsat time-series imagery from 1988 to 2018.

\section{Materials and Methods}

\subsection{Study Area}

Sistan, Baluchestan Province are located in South east Iran, The climate of the study area varies from arid to humid. Most parts of the province are arid and average of precipitation is $200 \mathrm{~mm}$ year -1 , but the main period of precipitation is during the winter. Temperature in most parts reaches above $45{ }^{\circ} \mathrm{C}$ during summer 


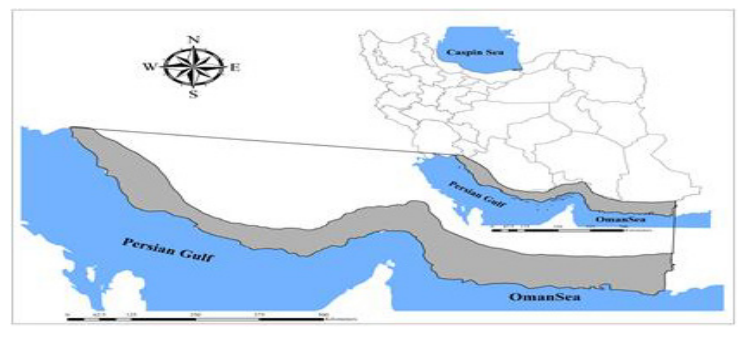

Figure 1. Location of the study area in Iran.

\subsection{Satellite data}

We used images of the study area acquired by Landsat (TM, $\mathrm{ETM}+$ and OLI) sensor at $30 \mathrm{~m} \times 30 \mathrm{~m}$ resolution from the Landsat database of U.S. Geological Survey (landsat.usgs.gov). We selected the cloud-free satellite images in the growing seasons of the study area, March to May, for the years 1988, 2018.

\subsection{Software used}

Satellite image processing to software, Idrisi (TerrSet) and ArcGIS 10.4 (Environmental Systems Research Institute (ESRI) product) were used to process, classify, analyses and display the satellite images

\subsection{Pixel-Based Classification}

The most common parametric classifier, maximum likelihood classification, has been used in this study. It is sums normal or near normal spectral distribution for each feature of interest and an equal prior probability among the classes (Li et al., 2011). The classification scheme was used based on the land use and land cover classification system provided, (Anderson et al., 1976) seven classes were identified: vegetation, Salty lands, water, Sandy lands, Lands built, Sand hill and mountain (Table 1). Prior to classification, all satellite data were interrogated using spectral and spatial profiles to ascertain the digital numbers (DNs) of different land cover categories. A combination of six Landsat TM layers (band 1 through 5 and 7) and seven Landsat 8 bands (band 1 through 7) were used to perform the maximum likelihood classification.

\section{5. Accuracy Assessment}

In general, the accuracy assessment determines the quality level of information extracted from remotely senseddata (Congalton \& Green, 2008). Classification accuracy refers to the rate of correspondence between the remotely sensed data and reference information (Congalton, 1991), (Dewan \& Yamaguchi, 2009). A common method for accuracy assessment is through the use of an error matrix which provides detailed information of the agreement between the classification results and reference information (Congalton $\&$ Green, 2008). Additionally, accuracy assessments such as overall accuracy, producer's accuracy, user's accuracy and overall kappa coefficient were carried out using the error matrices. Equation (1) was used to compute the kappa coefficient (Jensen, 2005)

$$
K=\frac{N \sum_{i=1}^{k} x_{i}-\sum_{i=1}^{k}\left(x_{i+} \times x_{+i}\right)}{N^{2}-\sum_{i=1}^{k}\left(x_{i} \times x_{+i}\right)}
$$

where $\mathrm{k}$ is the number of rows in the matrix; $\mathrm{xii}$ is the number of observations in row $\mathrm{i}$ and column $\mathrm{i}$; $\mathrm{x}+$ and $\mathrm{x}+\mathrm{i}$ are the marginal totals of row $\mathrm{k}$ and column $\mathrm{i}$ respectively; and $\mathrm{N}$ is the number of observations

\section{Results and Discussion}

\subsection{Image Classification}

The classification technique used to derive the LULC maps for 1988, and 2018 were the traditional maximum likelihood classification. The maximum likelihood classification is based on the probability that a pixel belongs to a particular class. The advantage of maximum likelihood classification is that it is less time consuming, but the disadvantage is that it increases the salt -and-pepper effect. Identifying a suitable segmentation image is extremely time consuming (Grimmond, 2007). In this study, pixel classification provided good LULC maps for chabahar and konarak. Analysis of Landsat images indicated that the most observed land cover changes in our study area are decrease vegetation cover and Lands built growth. The increase in Lands built and urbanization was clearly shown in chabahar and konarak from 1988 to 2018. Increased urbanization is a major concern in developing countries. It is expected that $60 \%$ of the world's population will live in urban areas by 2030 , and most of the urban growth will occur in less developed countries (Girard et al., 2003) , ( Rahman et al., 2011). Our results show that the expansion of urbanization has increased extensively in the rural areas surrounding chabahar and konarak. These lands have become part of the cities due to population growth and the related increase in industry and associated activities. The rapid growth of urban areas and the lack of planning frameworks have increased the impact on the ecosystem, particularly in the desert environment. 
Increasing of urbanization and population at higher rates than the national government's ability to provide services for sustainable healthy living environments can be a serious threat in the urban environment (Pauchard et al., 2006) (Grimmond, 2007). The results of this research indicate that the rate of urbanization was very fast and uncontrolled in both chabahar and konarak from 1988 to 2018. The major concern in these cities is the uncontrolled urban growth, which leads to environmental abuses and health risks.
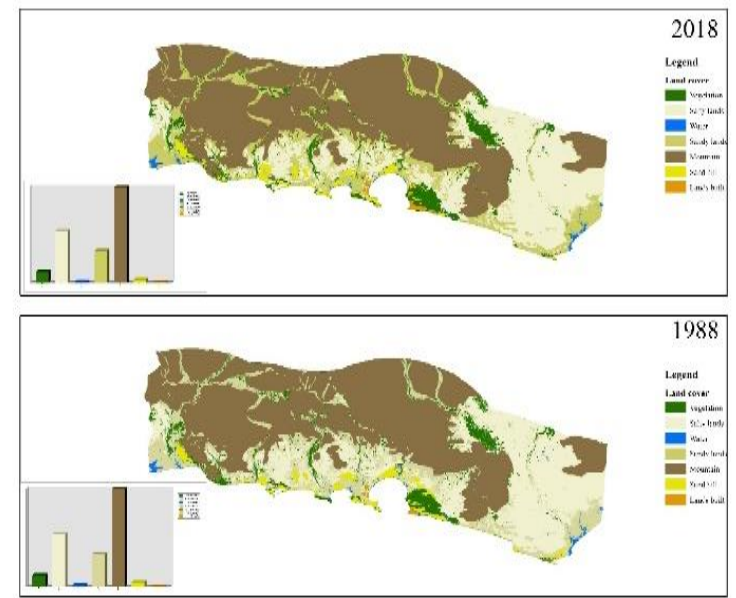

\section{Conclusions}

Figure 2. Land use/land cover in 1988, 2018

Table 1. Land use/land cover pattern during different years (Area in hectare)

\begin{tabular}{|c|c|c|}
\hline $\begin{array}{c}\text { Land use/land } \\
\text { cover classes }\end{array}$ & 1988 & 2018 \\
\hline vegetation & 90337.047 & 87974.241 \\
\hline Salty lands & 414366.437 & 418518.663 \\
\hline water & 8354.072 & 7507.506 \\
\hline Sandy lands & 254386.241 & 257153.856 \\
\hline mountain & 771605.834 & 771619.829 \\
\hline Sand hill & 33018.089 & 25676.169 \\
\hline Lands built & 1922.488 & 5487.395 \\
\hline
\end{tabular}

Land use change was examined in the region during the 2 periods. In this section, the results for the time of $1988-2018$ are presented. Based on the results of the 30-year time period, vegetation has been decreased in area while Lands built areas have been developed. The area of Salty lands has also increased This study assessed LULC changes in chabahar and konarak using Landsat images. The results can be summarized as follows: chabahar and konarak were found to have experienced rapid changes in LULC from 1988 to 2018. The Lands built areas increased by approximately 5487.395 ha in chabahar and konarak. The expansion of the urban areas and Lands built in chabahar and konarak exhibited clear spatiotemporal differences. Increasing urbanization, Accompanied with decreased vegetation cover over the study area due. In summary, Landsat images can provide the rate, patterns and trend of changes using the benefit of repetitive satellite coverage on a particular locality. Such information is essential for further planning and development in the future. 


\section{REFERENCES}

Alqurashi, A.F. and Kumar, L., 2014. Land use and land cover change detection in the Saudi Arabian desert cities of Makkah and Al-Taif using satellite data. Advances in Remote Sensing, 3(3), pp.106-119.

Behera, S., Ghanty, S., Ahmad, F., Santra, S. and Banerjee, S., 2012. UV-visible spectrophotometric method development and validation of assay of paracetamol tablet formulation. J Anal Bioanal Techniques, 3(6), pp.151-7.

Dubovyk, O., Sliuzas, R. and Flacke, J., 2011. Spatiotemporal modelling of informal settlement development in Sancaktepe district, Istanbul, Turkey. ISPRS Journal of Photogrammetry and Remote Sensing, 66(2), pp.235-246.

Azizi, A., Malakmohamadi, B. and Jafari, H.R., 2016. Land use and land cover spatiotemporal dynamic pattern and predicting changes using integrated CA-Markov model. Global Journal of Environmental Science and Management, 2(3), pp.223-234.

T. Ramachandra and U. Kumar.,2004. "Geographic Resources Decision Support System for Land Use, Land Cover Dy- namics Analysis," Proceedings of the FOSS/GRASS Us- ers Conference, Bangkok, September

Weng, Q. 2002. Land Use Change Analysis in the Zhujiang Delta of China Using Satellite Remote Sensing, GIS and Stochastic Modelling. Journal of Environmental Management, 64, 273-284.

Berlanga-Robles, C.A. and Ruiz-Luna, A.,2011. Integrating Remote Sensing Techniques, Geographical Information Systems (GIS), and Stochastic Models for Monitoring Land Use and Land Cover (LULC) Changes in the Northern Coastal Region of Nayarit, Mexico. GIScience \& Remote Sensing, 48, 245-263.

Li, G., Lu, D., Moran, E. and Hetrick, S.,2011. Land-Cover Classification in a Moist Tropical Region of Brazil with Landsat Thematic Mapper Imagery. International Journal of Remote Sensing, 32, 8207-8230.

Anderson, J.F., Hardy, E.E., Roach, J.T. and Witmer, R.E.,1976. A Land Use and Land Cover Classification System for Use with Remote Sensor Data. US Geological Survey Professional Paper 964, 28.

Congalton, R.G. and Green, K. ,2008. Assessing the Accuracy of Remotely Sensed Data: Principles and Practices. 2ndEdition, CRC Press, Boca Raton.

Congalton, R.G. ,1991. A Review of Assessing the Accuracy of Classifications of Remotely Sensed Data. Remote Sensing of Environment, 37, 35-46.

Dewan, A.M. and Yamaguchi, Y. ,2009. Land Use and Land Cover Change in Greater Dhaka, Bangladesh: Using Remote Sensing to Promote Sustainable Urbanization. Applied Geography, 29, 390-401.

Jensen, J.R. ,2005. Introductory Digital Image Processing: A Remote Sensing Perspective. 3rd Edition, Clarke, K.C., Ed., Prentice Hall, Upper Saddle River.
Girard, L.F., Forte, B., Cerreta, M., de Toro, P. and Forte, F. (Eds.) .,2005. The Human Sustainable City: Challenges and Perspectives from the Habitat Agenda. Ashgate, Aldershot

Rahman, A., Aggarwal, S.P., Netzband, M. and Fazal, S. ,2011. Monitoring Urban Sprawl Using Remote Sensing and GIS Techniques of a Fast Growing Urban Center, India. IEEE Journal of Selected Topics in Applied Earth Observations and Remote Sensing, 4, 56-64.

.Pauchar d, A., Aguayo, M., Peña, E. and Urrutia, R. ,2006. Multiple Effects of Urbanization on the Biodiversity of Developing Countries: The Case of a Fast-Growing Metropolitan Area (Concepción, Chile). Biological Conservation, 127, 272-281.

Grimmond, S. 2007. Urbanization and Global Environmental Change: Local Effects of Urban Warming. The Geographical Journal, 173, 83-88.

GIVEIE, A.Z., HAKIMZADEH, M.A., ZARE, M., EBRAHIMI, K.Z. and DASHTAKIAN, K., 2015. Monitoring of soil salinity using ASTER satellite data to evaluate desertification in the Marvast plain, Yazd province. 